\title{
Reduction of the Optical Losses in CdTe/ZnTe Thin-Film Solar Cells
}

\author{
S. Chusnutdinow ${ }^{a}$, R. Pietruszka ${ }^{a}$, W. ZaleszczyK ${ }^{a}$, V.P. Makhniy ${ }^{b}$, M. Wiater $^{a}$, \\ V. KOlKovskY ${ }^{a}$, T. WOJTOWICZ ${ }^{a}$ AND G. KARCZEWSKI ${ }^{a}$ \\ ${ }^{a}$ Institute of Physics, PAS, al. Lotników 32/46, 02-668 Warszawa, Poland \\ ${ }^{b}$ Yuri Fedkovych Chernivtsi National University, 2 Kotsyubynsky Str., 58012 Chernivtsi, Ukraine
}

\begin{abstract}
We report on reduction of optical losses in $n$-CdTe/ $/ p$-ZnTe thin-film solar cells grown by molecular beam epitaxy. The investigated thin-film devices were grown from elemental sources on monocrystalline, semi-insulating, (100)-oriented GaAs substrates. The optical losses have been reduced by a texturing of the device surface and by depositing of a $\mathrm{ZnO}$ antireflection coating. Current-voltage and spectral characteristics of the investigated $p$-ZnTe $/ n$-CdTe solar cells depend significantly on the preparation of the surface of the ZnTe window. We describe a procedure of chemical etching of the ZnTe window leading to surface texturing. A ZnO layer of proper thickness deposited by low-temperature atomic layer deposition technique on the ZnTe surface forms an effective antireflection coating that leads to the reduction of optical losses. Due to reduction of the optical losses we observe increase of the short-circuit current, $J_{\mathrm{SC}}$, by almost $60 \%$ and of the energy conversion efficiency by $44 \%$.
\end{abstract}

DOI: $10.12693 /$ APhysPolA.126.1072

PACS: 81.15.Hi, 73.61.Ga, 85.60.Dw, 88.40.jm

\section{Introduction}

The interest in application of solar cells for industrial electricity production has been increasing rapidly in recent years. The main goal of many research groups for the nearest future is to improve the efficiency of Si cells from the current efficiency of $22 \%$ [1] to the maximum theoretical efficiency of $29 \%$ [2] and of $\mathrm{CdTe} / \mathrm{CdS}$ cells from the current efficiency of $16 \%$ [1] to the maximum theoretical efficiency of $28 \%$ [3]. There are many reasons for the reduced energy conversion efficiency of the nowadays solar cells. They are related to optical, electrical and recombination losses. The optical losses are due to the surface reflection, reflection from the rear surface of the cell and shading by top electrical contact. There are two wellknown methods of reducing optical losses: minimization of the size of top contact and deposition of antireflection coatings (ARC) on the device surface. For different solar cell devices different thin films are used as ARC, including: $\mathrm{TiO}_{2}, \mathrm{ITO}, \mathrm{Al}_{2} \mathrm{O}_{3}, \mathrm{SiO}_{2}, \mathrm{SiN}_{x}, \mathrm{MgF}_{2}$ and $\mathrm{ZnO}$ [4-8]. The reflection can also be reduced by surface texturing. Textured surfaces have an advantage of a light-trapping due to their reduced reflection and increased optical path length in reflection or absorption. The solar cells can be textured using a photolithographic technique [9], chemical and electrochemical etching $[10,11]$ and reactive ion etching (RIE) [12, 13].

Here, we report on an our attempt to reduce optical losses by the either surface texturing or formation of ARC on the top of $n$-CdTe $/ p$-ZnTe thin-film solar cells grown by molecular beam epitaxy (MBE).

\section{Experimental}

The investigated $p$-ZnTe $/ n$-CdTe heterostructures were grown by MBE on semi-insulating, (100)-oriented
GaAs substrates in ultrahigh vacuum EPI 620 MBE system. Firstly, a $13 \mu \mathrm{m}$ thick, highly iodine doped $n$-type CdTe buffer was grow at the reduced substrate temperature of about $250^{\circ} \mathrm{C}$, with the purpose of increasing electron concentration. The best contact layers grown this way exhibited carrier concentrations around $10^{19} \mathrm{~cm}^{-3}$. The $n$-CdTe buffer was then covered by $2 \mu \mathrm{m}$ thick, undoped CdTe and subsequently by $1.5 \mu \mathrm{m}$ of nitrogenplasma doped $p$-type ZnTe. For the growth of the intrinsic CdTe and $p$-type ZnTe the growth temperature was elevated to $30^{\circ} \mathrm{C}$.

Surface texturing of the top ZnTe layer was done by electrochemical etching in acidic solution composed of $\mathrm{HNO}_{3}: \mathrm{HCl}: \mathrm{H}_{2} \mathrm{O}$ at a mixing ratio of 1:4:20. During the etching process the structure with top side contact to ZnTe made of Au constituted anode and another electrode was made of platinum wire. Various voltages between electrodes, from $0.5 \mathrm{~V}$ to $2 \mathrm{~V}$, were applied during process. After etching the samples were rinsed in deionized water, dipped in a solution of polysulfide to remove oxidation products, and then rinsed again in de-ionized water [14]. In order to produce antireflection coatings and transparent contacts the Al-doped $\mathrm{ZnO}$ (AZO) thinfilms were grown by atomic layer deposition (ALD) technique in a Savannah-100 reactor (Cambridge NanoTech). For the growth diethylzinc $\left(\mathrm{Zn}\left(\mathrm{C}_{2} \mathrm{H}_{5}\right)_{2}\right)$ and water vapor were used as zinc and oxygen precursors, respectively. For doping with aluminum, trimeth-ylaluminum (TMA) was used. Growth temperature was $160^{\circ} \mathrm{C}$.

The thickness of $\mathrm{ZnO}$ films was measured by a Mikropack NanoCalc 2000 reflectometer. The thickness of the antireflection films was around $100 \mathrm{~nm}$. $\mathrm{ZnO}$ were deposited on the untreated surface of the structures. Gold ohmic contacts to $n$ - $\mathrm{ZnO}$ were deposited by e-beam evaporation (in PREVAC 190 System). Prior to 
the formation of ohmic contact to the $n$-type CdTe layer the top-most layers of $\mathrm{ZnO}, \mathrm{ZnTe}$, and intrinsic $\mathrm{CdTe}$ were removed by etching in Br-methanol. The contact was formed by In soldering to the exposed $n$-type CdTe buffer. Photovoltaic response was measured using a source-meter Keithley 2601 with Solar Simulator LS0308 class A, at illumination irradiance of $100 \mathrm{~mW} / \mathrm{cm}^{2}$. Data processing was performed using Software package Tracer 2 ReRa Solutions. Quantum efficiency was measured using a PV quantum efficiency system (185-1100 nm; SPEQUEST system, ReRa Solutions).

\section{Results and discussion}

\subsection{Morphological study and optical characterization}

Figure 1 shows the typical scanning electron microscopy (SEM) image of a surface etched at $+1 \mathrm{~V}$. During the etching process the current was time dependent. We observe a strongly corrugated surface structure with etch pits of different sizes and forms. The size of etch pits varies from $50 \mathrm{~nm}$ to $200 \mathrm{~nm}$ (Fig. 1a,b). For etching times longer than $40 \mathrm{~s}$ the surface becomes covered by very fine needles with diameters of several $\mathrm{nm}$ (see Fig. 1c,d). For further studies we used samples etched for $40 \mathrm{~s}$ and having on the surfaces etch pits of size 150$200 \mathrm{~nm}$.

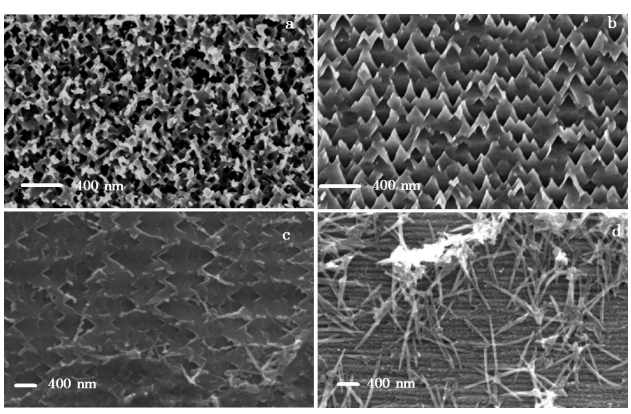

Fig. 1. SEM image of the top $p$-ZnTe layer that was electrochemically etched at $+1 \mathrm{~V}$ in $\mathrm{HNO}_{3}: \mathrm{HCl}: \mathrm{H}_{2} \mathrm{O}$ solution for the period of: (a) $20 \mathrm{~s}$, (b) $40 \mathrm{~s}$, (c) $60 \mathrm{~s}$, (d) $80 \mathrm{~s}$.

The results of the measurement of quantum efficiency of the etched structure is presented in Fig. 2, and compared with that of unprocessed structure and structure covered by $\mathrm{ZnO}$ antireflective coating (see further). As can be seen in Fig. 2, surface modification by electrochemical etching does not increase quantum efficiency noticeably.

The next approach to reduce optical losses was ALD deposition of thin AZO film on the top surface of the solar cells. Additional advantage of the AZO films is that they are very good candidates for transparent contacts. That is because they are known to be highly conductive and their optical transparency in a wide spectral region exceeds $90 \%$ [15]. The refractive index of AZO (1.954) is

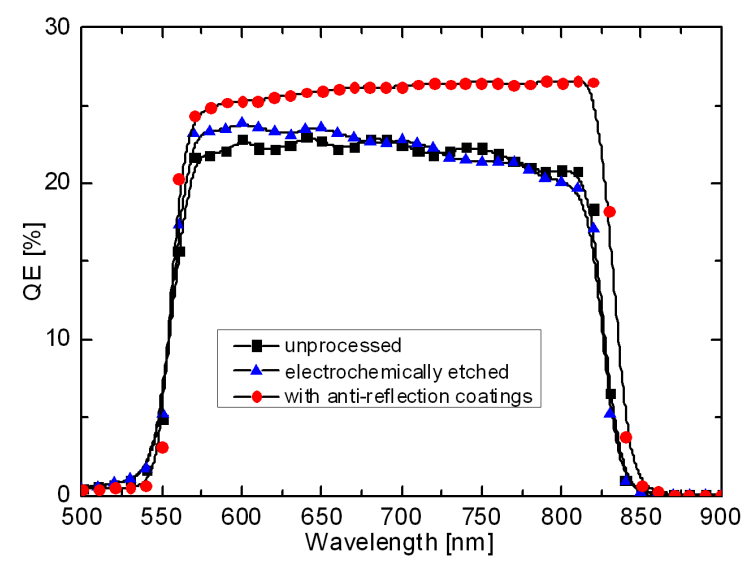

Fig. 2. Quantum efficiency as a function of wavelength measured at room temperature for three typical $\mathrm{CdTe} / \mathrm{ZnTe}$ solar cells: one unprocessed and two after our attempts to reduce optical losses.

smaller than the refractive indexes of both $\mathrm{ZnTe}(2.835)$ and CdTe (2.968) at $820 \mathrm{~nm}$. Because of this, the AZO films reduce the reflectance of $\mathrm{CdTe} / \mathrm{ZnTe}$ solar cells from $20 \%$ down to $2 \%$ at $820 \mathrm{~nm} \mathrm{[16].} \mathrm{As} \mathrm{a} \mathrm{result} \mathrm{the} \mathrm{external}$ quantum efficiency increases by almost $5 \%$ in the absorption range of $\mathrm{CdTe}$, as can be seen in Fig. 2. Another effect of antireflection coating is the disappearance of the Fabry-Perot oscillation, also visible in Fig. 2.

\subsection{Solar cells properties}

Figure 3 shows the $J-V$ characteristic for the three types of $\mathrm{CdTe} / \mathrm{ZnTe}$ solar cells, used in these studies. They can be well described by the diode Shockley equation for real solar cells with the parasitic resistances

$$
J=J_{0}\left(\exp \left(\frac{q\left(V-J R_{S}\right)}{n k T}\right)-1\right)+\frac{V-J R_{S}}{R_{S h}}-J_{P h},
$$

where $J_{P h}$ is the photocurrent, $J_{0}$ is the dark saturation current and $n$ is the diode ideality factor (which depends on the current flow mechanism), $R_{S}$ the series resistance, and $R_{S h}$ is the shunt resistance. To a first approximation the $R_{S}$ and $R_{S h}$, can be determined from the slopes of the $J-V$ curve at $V=V_{\mathrm{OC}}$ and $J=J_{\mathrm{SC}}$, respectively. Here $V_{\mathrm{OC}}$ is an open circuit voltage and $J_{\mathrm{SC}}$ is a short circuit current. The open-circuit voltage, $V_{\mathrm{OC}}$, is the maximum voltage available from a solar cell, and this occurs at zero current. The short-circuit current, $J_{\mathrm{SC}}$, is the current through the solar cell when the voltage across the solar cell is zero. $R_{S h}$ is represented by the slope at $J_{\mathrm{SC}}$. Typically, the resistances at $J_{\mathrm{SC}}$ and at $V_{\mathrm{OC}}$ determined from data curve in Fig. 3 and to show in Table. From Eq. (1) we obtain the open circuit voltage by setting $J=0$ and $R_{S h} \gg R_{S}$ :

$$
J_{P h} \approx J_{\mathrm{SC}} \approx J_{0}\left(\exp \left(\frac{q V_{\mathrm{OC}}}{n k T}\right)-1\right) .
$$

Hence

$$
\ln \left(J_{\mathrm{SC}}\right)=\ln \left(J_{0}\right)+\frac{q V_{\mathrm{OC}}}{n k T} .
$$




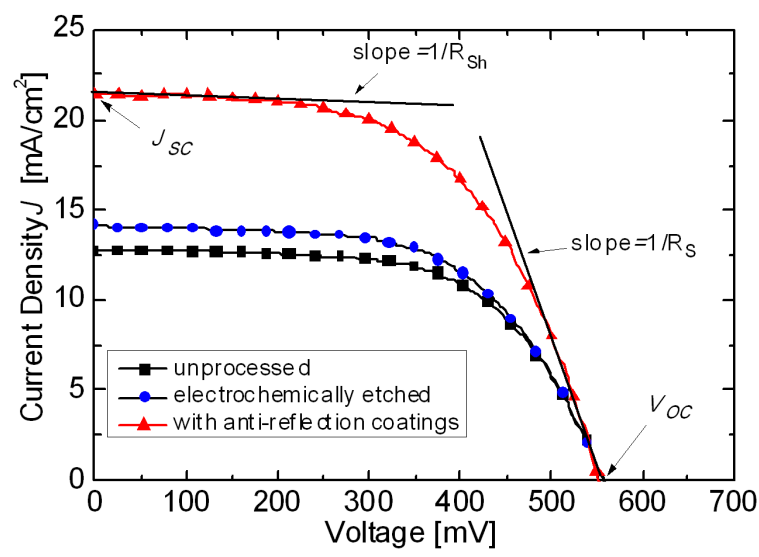

Fig. 3. Typical $J--V$ characteristics of various types of $\mathrm{CdTe} / \mathrm{ZnTe}$ solar cells collected under illumination of $100 \mathrm{~mW} \cdot \mathrm{m}^{-2}$.

TABLE I

Average series resistance $\left(R_{S}\right)$, shunt resistance $\left(R_{S h}\right)$, open circuit voltage $\left(V_{\mathrm{OC}}\right)$, short circuit current $\left(J_{\mathrm{SC}}\right)$, fill factor $(\mathrm{FF})$ and efficiency $(\eta)$ for $\mathrm{CdTe} / \mathrm{ZnTe}$ solar cells. These photovoltaic parameters were measured under AM 1.5 illumination at $100 \mathrm{~mW} \mathrm{~cm}^{-2}$ at $300 \mathrm{~K} .1$ - structure without any processing toward reduction of optical losses, 2 - structure that was electrochemically etched, 3 structure with antireflection coatings.

\begin{tabular}{c|c|c|c|c|c|c|c|c}
\hline \hline & $\begin{array}{c}J_{\mathrm{SC}} \\
{\left[\mathrm{mA} / \mathrm{cm}^{2}\right]}\end{array}$ & $\begin{array}{c}V_{\mathrm{OC}} \\
{[\mathrm{mV}]}\end{array}$ & $\begin{array}{c}\mathrm{FF} \\
{[\%]}\end{array}$ & $\begin{array}{c}\eta \\
{[\%]}\end{array}$ & $\begin{array}{c}R_{S h} \\
{\left[\Omega \cdot \mathrm{cm}^{2}\right]}\end{array}$ & $\begin{array}{c}R_{S} \\
{\left[\Omega \cdot \mathrm{cm}^{2}\right]}\end{array}$ & $\begin{array}{c}J_{0} \\
{\left[\mathrm{~mA} / \mathrm{cm}^{2}\right]}\end{array}$ & $n$ \\
\hline 1 & 12.77 & 556.3 & 61.5 & 4.4 & 893 & 11 & $6.02 \times 10^{-5}$ & 1.8 \\
2 & 13.89 & 555.4 & 59.5 & 4.6 & 567 & 10 & $5.7 \times 10^{-5}$ & 1.7 \\
3 & 21.48 & 552.0 & 56.6 & 6.7 & 690 & 6.8 & $2.8 \times 10^{-5}$ & 1.5
\end{tabular}

Using this equation, the values of $n$ and $J_{0}$ can be determined from the measured values of $J_{\mathrm{SC}}$ and $V_{\mathrm{SC}}$ at different levels of illumination, as presented in Fig. 4 for the unprocessed structure. The results of such procedure are presented in Table together with other parameters, as described in the caption. Determined ideality parameter $n$ is in the range from 1 to 2 , and the saturation $J_{0}$ current varies in the range of $10^{-4}-10^{-5} \mathrm{~mA} / \mathrm{cm}^{2}$ at $300 \mathrm{~K}$, which is typical for this type of diodes [17]. The value of the diode ideality factor indicates that the dominant carrier recombination in the space charge region takes place on the deep-level defects with the hole activation energy $0.78 \mathrm{eV}$ and concentration $\approx 10^{13} \mathrm{~cm}^{-3}$. Most probably these defects are created due to the $\mathrm{CdTe} / \mathrm{ZnTe}$ lattice mismatch [18]. It can be seen in Fig. 3 that the $J-V$ curve under illumination for structure that was electrochemical etched showed small change in comparison to $J-V$ curve for unetched structure. Figure 3 shows also the $J-V$ curve of the solar cell that was antireflection coated. We observe that the current density $J_{\mathrm{SC}}$ increases by almost $60 \%$ and that the efficiency increases by $44 \%$, from 4.5 to $6.5 \%$. The $V_{\mathrm{OC}}$ does not change. The average photovoltaic parameters are presented in Table.

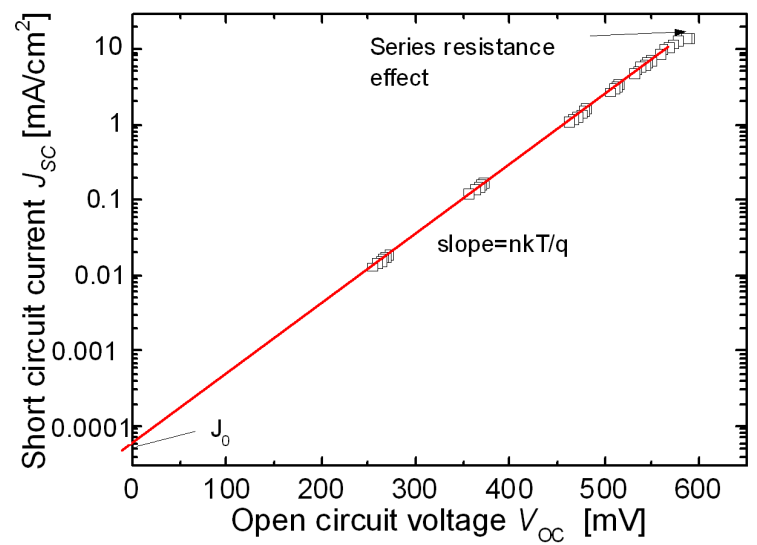

Fig. 4. Short-circuit current versus open-circuit voltage illustrating the method of parameters extraction for unprocessed structure.

\section{Conclusions}

We have found that in the $\mathrm{CdTe} / \mathrm{ZnTe}$ solar cells the optical losses can be reduced much more efficiently by depositing of antireflection coatings than by surface texturing produced via electrochemical etching with $\mathrm{HNO}_{3}: \mathrm{HCl}: \mathrm{H}_{2} \mathrm{O}$. Even after optimal electrochemical etching procedure we observed the etch pits with sizes, in the range $50-200 \mathrm{~nm}$, which are too small to reduce reflectance. On the other hand, all four important solar cell parameters such as short circuit current density $\left(J_{\mathrm{SC}}\right)$, efficiency $(\eta)$, ideality factor $(n)$ and series resistance $\left(R_{S}\right)$ improve when the $\mathrm{ZnO}$ layers are deposited on the top surface of solar cells. An increase of relative current density by $60 \%$ and of efficiency by $44 \%$ was observed.

\section{Acknowledgments}

This work was supported by the European Union within the European Regional Development Fund through the Innovative Economy grant MIME (POIG.01.01.02-00-108/09).

\section{References}

[1] M.A. Green, K. Emery, Y. Hishikawa, W. Warta, E.D. Dunlop, Prog. Photovolt Res. Appl. 22, 1 (2014).

[2] A. Richter, M. Hermle, S.W. Glunz, IEEE J. Photovolt. 3, 1184 (2013).

[3] A.L. Fahrenbruch, R.H. Bube, Fundamentals of Solar Cells: Photovoltaic Solar Energy Conversion, Academic Press, New York 1983.

[4] H. Mackel, R. Ludemann, J. Appl. Phys. 92, 602 (2002).

[5] M. Barrera, J. Pla, C. Bocchi, Sol. Energy Mater. Sol. Cells 92, 1115 (2008).

[6] G. Zhang, J. Zhao, M.A. Green, Sol. Energy Mater. Sol. Cells 51, 393 (1998). 
[7] S.I. Muramatsu, T. Uetmatsu, H. Ohtsuka, Y. Yazawa, T. Warabisako, H. Nagayoshi, K. Kamisako, Sol. Energy Mater. Sol. Cells 65, 599 (2001).

[8] Y.F. Makableh, R. Vasan, J.C. Sarker, A.I. Nusir, S. Seal, M.O. Manasreh, Solar Energy Mater. Solar Cells 123, 178 (2014).

[9] J.A.W. Zhao, X. Dai, M.A. Green, S.R. Wenham, in: 22nd IEEE PV Specialists Conf., 1991, p. 399.

[10] E. Vazsonyi, K. de Clercq, R. Einhaus, E. van Kerschaver, K. Said, J. Poortmans, J. Szlufcik, J. Nijs, Sol. Energy Mater. Sol. Cells 57, 179 (1999).

[11] M.J. Sailor, in: Porous Silicon in Practice: Preparation, Characterization and Applications, Wiley-VCH Verlag, Weinheim 2011, p. 5.

[12] T. Wells, M.M. El-Gomati, J.J. Wood, J. Vac. Sci. Technol. B 15, 397 (1997).
[13] J. Yoo, Kyunghae Kim, M. Thamilselvan, N. Lakshminarayn, Young Kuk Kim, Jaehyeong Lee, Kwon Jong Yoo, Junsin Yi, J. Phys. D: Appl. Phys. 41, 125205 (2008).

[14] F. Zenia, C. Lěvy-Clěment, R. Triboulet, R. Könenkamp, K. Ernst, M. Saad, M.C. Lux-Steiner, Appl. Phys. Lett. 75, 531 (1999).

[15] G. Luka, T.A. Krajewski, B.S. Witkowski, G. Wisz, I.S. Virt, E. Guziewicz, M. Godlewski, J. Mater. Sci. Mater. Electron. 22, 1810 (2011).

[16] http://filmetrics.com/reflectance-calculator .

[17] S. Chusnutdinow, V.P. Makhniy, T. Wojtowicz, G. Karczewski, Acta Phys. Pol. A 122, 1077 (2012).

[18] G. Karczewski, S. Chusnutdinow, K. Olender, T. Wosiński, T. Wojtowicz, Phys. Status Solidi C 11, 1296 (2014). 